\title{
Isolation of Helicobacter pylori from Gastric Biopsy of Dyspeptic Patients in Ghana and In Vitro Preliminary Assessment of the Effect of Dissotis rotundifolia Extract on Its Growth
}

\author{
Michael Buenor Adinortey ${ }^{(D)},{ }^{1}$ Charles Ansah, ${ }^{2}$ Cynthia Ayefoumi Adinortey ${ }^{(D},^{3}$ \\ Ansumana Sandy Bockarie, ${ }^{4}$ Martin Tangnaa Morna, ${ }^{4}$ and Damian H. Amewowor ${ }^{3}$ \\ ${ }^{1}$ Department of Biochemistry, School of Biological Sciences, College of Agriculture and Natural Sciences, University of Cape Coast, \\ Cape Coast, Ghana \\ ${ }^{2}$ Department of Pharmacology, Faculty of Pharmacy and Pharmaceutical Sciences, Kwame Nkrumah University of Science and \\ Technology, Kumasi, Ghana \\ ${ }^{3}$ Department of Molecular Biology and Biotechnology, School of Biological Sciences, College of Agriculture and Natural Sciences, \\ University of Cape Coast, Cape Coast, Ghana \\ ${ }^{4}$ Department of Internal Medicine, School of Medical Sciences, College of Health and Allied Sciences, University of Cape Coast, \\ Cape Coast, Ghana
}

Correspondence should be addressed to Michael Buenor Adinortey; madinortey@ucc.edu.gh

Received 22 July 2018; Accepted 30 September 2018; Published 31 October 2018

Academic Editor: Marcel Tanner

Copyright (C) 2018 Michael Buenor Adinortey et al. This is an open access article distributed under the Creative Commons Attribution License, which permits unrestricted use, distribution, and reproduction in any medium, provided the original work is properly cited.

\begin{abstract}
Helicobacter pylori (H. pylori) is a gram-negative bacterium that colonizes the human stomach. Infection with this microaerophilic bacterium causes gastric and duodenal ulcer. This study sought to isolate $H$. pylori, from gastric biopsy samples of dyspeptic patients in Ghana using a 2,3,5-triphenyltetrazolium chloride (TTC) dye incorporated medium method. This TTC dye method was further used in an antimicrobial susceptibility assay involving Dissotis rotundifolia extract (DRE). H. pylori were successfully isolated from gastric biopsy of dyspeptic patients. Pure cultures of $\mathrm{H}$. pylori in 2,3,5-triphenyltetrazolium chloride (TTC) dye incorporated medium were seen as sparkling colonies. Isolates, identified as $H$. pylori, were gram-negative and urease, catalase, and oxidase positive and showed characteristic morphology as spiral-shaped bacteria under the microscope. The organisms were found to be susceptible to cephalothin and resistant to nalidixic acid. Above all, the observation that $H$. pylori grew only at $37^{\circ} \mathrm{C}$ and not $25^{\circ} \mathrm{C}$ or $42^{\circ} \mathrm{C}$ affirms that the bacterium is neither Helicobacter cinaedi nor Helicobacter fenneliae. The anti- $H$. pylori study depicts a statistically lower zone of inhibition for DRE compared to standard drugs [amoxicillin and clarithromycin] $(\mathrm{p}<0.05)$, whereas metronidazole showed no zone of inhibition. This study reports the first successful isolation and culturing of $H$. pylori in Ghana using TTC dye. It also shows that DRE possess an in vitro anti- H. pylori activity and that DRE has some therapeutic potential against H. pylori infection.
\end{abstract}

\section{Introduction}

The discovery of Helicobacter pylori (H. pylori) in 1982 [1] was the beginning of a transformation concerning the management of gastroduodenal diseases. The public health relevance of the discovery and its role in gastrointestinal diseases was recognized in 2005 by the credit of the Nobel
Prize in Physiology or Medicine to B. Marshall and R. Warren [2]. H. pylori is a gram-negative bacterium that colonizes the human stomach. Infection with this gram-negative organism is linked with gastritis and peptic ulcer diseases which when improperly managed may eventually result in the development of gastric adenocarcinoma and mucosa-associated lymphoid tissue (MALT) lymphoma [3]. The invasion of the 
stomach by this fastidious bacterium results in an imbalance between aggressive and defense factors. Among peptic ulcer patients, $H$. pylori is reported to be the main etiological agent with an overall prevalence rate of about $25-30 \%$ in developed countries, and over $80 \%$ in developing countries in peptic ulcer patients [4]. H. pylori is reported to be a major cause of at least $90 \%$ of duodenal ulcers and $70 \%$ of gastric ulcers [5]. Eradication of $H$. pylori has been reported to result in peptic ulcer healing, prevention of recurrence, and reduction in the prevalence of gastric cancer in high-risk populations [6].

Though several studies have been conducted on $H$. pylori in Ghana [7-12], no report is available on the use of the culture method. The unsuccessful attempts to use the culture technique have made it impossible to deploy antimicrobial susceptibility assay methods and also characterize $H$. pylori strains in Ghana. This for a long time has slowed down research involving the use of $H$. pylori and associated infections in Ghana. This challenge has made it virtually impossible to obtain information regarding drug resistance profile of $H$. pylori in Ghana, which has slackened research progress in healthcare for peptic ulcer patients. This study sought to isolate $H$. pylori from gastric biopsy samples of dyspeptic patients by using a modified culturing technique involving 2,3,5-triphenyltetrazolium chloride (TTC) dye. The adaptability of this culturing method was subsequently tested in a susceptibility assay to determine the anti- $H$. pylori effects of extracts of Dissotis rotundifolia on clinical isolates using the agar well diffusion assay method.

\section{Materials and Methods}

2.1. Chemicals, Drugs, and Other Consumables. The following chemicals, drugs, and test kits were used for the experiments: urease test kit (ClO test) was obtained from USA. Brain Heart Infusion (BHI) agar, Brain Heart Infusion (BHI) broth, Skirrow's supplement (SR69) Oxoid England, glycerol, cephalothin $(30 \mu \mathrm{g})$, and nalidixic acid $(30 \mu \mathrm{g})$ antibiotic disc were obtained from Mast Group Ltd., Merseyside, UK. GasPak EZ Campy Container System was obtained from Becton Dickinson, USA. Sodium hydroxide, magnesium chloride, sucrose, glucose, methanol (99.8\%), and ethanol (99.8\%) were obtained from British Drug House, (BDH) (London, UK). 2,3,5-Triphenyltetrazolium chloride (TTC) was obtained from Sigma Aldrich. Expired blood was obtained from the Blood Bank of the Cape Coast Regional hospital, Cape Coast, Ghana.

\subsection{Collection of Plant Material and Extraction Method.} Dissotis rotundifolia whole plant was collected from the environment around the Kakum National Park, Cape Coast, Ghana, and validated by a curator at the Herbarium of the University of Cape Coast. A voucher specimen (No. 107346) was prepared and deposited at the herbarium. The whole plant was thoroughly washed, shade-dried for three weeks, oven-dried at $40^{\circ} \mathrm{C}$ for $4 \mathrm{~h}$, and then milled into powder. The method of extraction described by Rath et al. [13] involving the sequential use of dichloromethane and $70 \%$ methanol was employed in the preparation of the crude whole plant extract.
The obtained crude DRE was stored at $-20^{\circ} \mathrm{C}$ until it was ready for use.

\subsection{Preparation of Media}

Christensen's Urea. Peptone (0.08 g), $0.4 \mathrm{~g} \mathrm{NaCl}, 0.16 \mathrm{~g} \mathrm{H}_{2} \mathrm{PO}_{4}$, $0.08 \mathrm{~g}$ D-glucose, and $1.6 \mathrm{~g}$ of agar powder were transferred into a conical flask. Distilled water $(72 \mathrm{~mL})$ was added and the mixture was microwaved to ensure complete dissolution. It was then allowed to cool sufficiently to $50^{\circ} \mathrm{C}$ before phenol red $(480 \mu \mathrm{L})$ was added. The $\mathrm{pH}$ of the mixture was adjusted to 6.30 and the medium was autoclaved at $121^{\circ} \mathrm{C}$ for 15 minutes. Urea $(1.6 \mathrm{~g})$ was dissolved in $8 \mathrm{~mL}$ of sterile distilled water and added to the medium. The medium was poured aseptically into test tubes, allowed to solidify in a slanted position, and stored.

Amended Brain Heart Infusion Blood Agar. Dehydrated powdered Brain Heart Infusion agar (5.20 g) was transferred into a $250 \mathrm{~mL}$ Erlenmeyer flask. Distilled water $(100 \mathrm{~mL})$ was added. The mixture was heated briefly in a microwave until the agar was completely dissolved. The flask was corked with cotton wool plug and it was autoclaved at $121^{\circ} \mathrm{C}$ for 15 minutes and allowed to cool to approximately $50^{\circ} \mathrm{C}$. Expired human blood $(7 \mathrm{~mL})$ was then added to the Brain Heart Infusion agar and $0.1 \mathrm{~g}$ of tetrazolium salt dissolved in 10 $\mathrm{mL}$ sterile distilled water was added. Skirrow's supplement (SR69) (Oxoid, England), vancomycin (5 mg), polymyxin $\mathrm{B}(2.5 \mathrm{mg})$, and trimethoprim $(2.5 \mathrm{mg})$ were also added to the medium to suppress the growth of other bacteria and fungi. The mixture was swirled and was poured aseptically into sterile Petri dishes. The agar plates were then allowed to solidify and later kept in a refrigerator.

Brain Heart Infusion Broth as Transport Medium. Brain Heart Infusion (BHI) broth was used as the transport medium for the transportation of gastric biopsy samples obtained from the Endoscopy Laboratory. Broth was prepared by transferring $4.2624 \mathrm{~g}$ of the Brain Heart Infusion broth powder into a clean conical flask and $114.48 \mathrm{~mL}$ of sterile distilled water was added. Glycerol $(28.8 \mathrm{~mL})$ representing about $20 \%$ of total solution was added to the solution and swirled until it was uniformly mixed. Cysteine solution $(0.72 \mathrm{~mL})$ of $0.2 \mathrm{~g} / \mathrm{L}$ prepared by dissolving $0.5 \mathrm{~g}$ of cysteine powder in $2.5 \mathrm{~mL}$ of $1 \mathrm{~N} \mathrm{HCl}$ was also added to the mixture and the $\mathrm{pH}$ of the mixture was adjusted to 7.40. The BHI broth was then transferred into McCartney's bottles. Each of the bottles containing $18 \mathrm{~mL}$ of the broth was autoclaved at $121^{\circ} \mathrm{C}$ for 15 minutes and stored in a refrigerator.

Brain Heart Infusion Broth for Antimicrobial Assay. The broth was prepared by transferring $2.96 \mathrm{~g}$ of the Brain Heart Infusion (BHI) broth powder into a clean conical flask and adding $76 \mathrm{~mL}$ of distilled water. It was then autoclaved at $121^{\circ} \mathrm{C}$ for 15 minutes and allowed to cool. Sterile inactivated human serum $(4 \mathrm{~mL})$ representing $5 \%$ of medium was added and the mixture swirled until it was uniformly mixed. Skirrow's reagent was also added as a supplement. Then 5 $\mathrm{mL}$ of the mixture was transferred into clean test tubes that 
were corked with cotton wool and stored at $-20^{\circ} \mathrm{C}$ until it was needed. Sterility quality control was performed by incubating an aliquot of the broth mixture at $37^{\circ} \mathrm{C}$ for $48 \mathrm{hrs}$.

\subsection{Isolation of $\mathrm{H}$. pylori}

Collection and Transportation of Gastric Biopsy. Antral and corpus gastric mucosal biopsy specimens were taken from dyspepsia patients referred to Life Science Laboratory, Cape Coast, for endoscopy after informed consent was obtained from patients and approval of proposal by the Institutional Review Board of the University of Cape Coast. Biopsies confirmed to be positive for $H$. pylori using urease test kit were immediately placed in sterile McCartney bottles containing $0.2 \mathrm{~g} / \mathrm{L}$ of cysteine and $20 \%$ glycerol in brain heart infusion (BHI) broth and transported on ice to the laboratory within 60 minutes of collection for subsequent analysis.

Inoculation of Gastric Biopsy. The BHI broth containing the gastric biopsy was homogenized using the WiseTis homogenizer HG-15D, Germany, at $5000 \mathrm{rpm}$ for 30 seconds to produce an evenly distributed mixture of biopsy tissue in the broth. The homogenized biopsy was then inoculated onto the brain heart infusion blood-amended agar. The inoculation was done, by dipping a flamed inoculation loop that has cooled for some time into the McCartney's bottle containing the homogenized biopsy tissue. The loop was used to streak the surface of an amended Brain Heart Infusion blood agar plate. The inoculation loop was flamed until they were redhot after usage. The inoculated plates were then packed in an inverted manner into gaspak air-tight container and a gaspak kit that generates microaerophilic conditions $\left(80 \% \mathrm{~N}_{2}, 10 \%\right.$ $\mathrm{CO}_{2}$, and $5 \% \mathrm{O}_{2}$ ) for the growth of $H$. pylori was included in the container. The replicated inoculated plates together with the gas generating kit were incubated at $25^{\circ} \mathrm{C}, 37^{\circ} \mathrm{C}$, and $42^{\circ} \mathrm{C}$ for 3-7 days.

Subculturing of Bacterial Isolates. After 3-7 days of incubation, sparkling colonies were only observed on the amended $\mathrm{BHI}$ blood agar cultured at $37^{\circ} \mathrm{C}$. A flamed inoculation loop was used to pick a single sparkling colony and streaked on the surface of a freshly amended BHI blood agar plate and incubated under microaerophilic conditions at $37^{\circ} \mathrm{C}$ for another 3-7 days to obtain pure cultures of $H$. pylori.

2.5. Microscopy and Biochemical Tests for Identification of $H$. pylori. H. pylori isolates were identified based on colony morphology and physical characteristics in the presence of TTC dye. Biochemical tests, namely, gram staining reaction, oxidase, urease, and catalase tests, and antibiotics (cephalothin and nalidixic acid) susceptibility test were employed [14, 15].

Susceptibility Test for H. pylori Using Nalidixic Acid and Cephalothin Antibiotics. A bacterial suspension was prepared by using a sterile inoculation loop to pick 3 discrete colonies of pure culture of $\mathrm{H}$. pylori growing on BHI blood agar amended with Skirrow's supplement and TTC dye. These colonies were transferred into a test tube containing $5 \mathrm{~mL}$ of sterile normal saline and the bacterial suspension was briefly vortexed to ensure even distribution of bacteria.

About $0.1 \mathrm{~mL}$ of the $H$. pylori bacterial suspension was transferred unto the surface of an amended BHI blood agar plate and spread over the entire surface of the agar plate. With the aid of sterile forceps, cephalothin and nalidixic acid discs were placed on the surface of inoculated plate and incubated at $37^{\circ} \mathrm{C}$ for 3-6 days under microaerophilic conditions.

2.6. Assessment of DRE for Anti-H. pylori Activity. Bacterial suspensions of $H$. pylori were adjusted to the McFarland turbidity standards corresponding to $1.5 \times 10^{8} \mathrm{CFU} / \mathrm{mL}$. Agar wells were punched in sterile amended BHI blood agar plates using a sterile stainless $6 \mathrm{~mm}$ cork borer and allowed to dry for 3-5 minutes. The wells were then filled with $65 \mu \mathrm{L}$ each of different concentrations of the DRE $(200,400,600$, and 800 $\mathrm{mg} / \mathrm{mL}$ ), while distilled water was used as negative control and $0.05 \mu \mathrm{g} / \mathrm{mL}$ clarithromycin, $0.05 \mu \mathrm{g} / \mathrm{mL}$ amoxicillin, and $500 \mu \mathrm{g} / \mathrm{mL}$ metronidazole were used as positive controls. The inoculated plates were incubated at $37^{\circ} \mathrm{C}$ for 3-6 days under microaerophilic condition. After the incubation period, the diameters of the clear zones of inhibition around the agar wells were measured. The tests were done in triplicate. The mean zones of inhibition were calculated and presented as bar graphs.

2.7. Data Analysis. Statistical analysis was performed on data using the GraphPad prism version 6.0. ANOVA was used to determine differences in mean values and also if there was any statistically significant difference in the diameter of zones of inhibition of the DRE samples and antibiotics. Values were considered significant when $P<0.05$ followed by Bonferroni's pairwise post hoc test where there was a significant difference among means.

\section{Results}

In this study, $H$. pylori were successfully isolated from the gastric biopsy of dyspepsia patients. Pure cultures of $H$. pylori in TTC dye incorporated medium were obtained as sparkling colonies (Figure 1). Isolates, identified as $H$. pylori, were gram-negative and urease, catalase, and oxidase positive and showed a characteristic morphology under the microscope. The organisms were also found to be susceptible to cephalothin and resistant to nalidixic acid (Figure 2).

The whole plant of Dissotis rotundifolia extract (DRE) was screened for its potential in inhibiting growth of $H$. pylori. DRE and standard antibiotic drugs [amoxicillin (AMX), clarithromycin (CLA)] showed antimicrobial activity against 5 confirmed $H$. pylori isolates (Figure 3 ). The diameters of the zones of inhibition ranged from 13 to $30 \mathrm{~mm}$ (Figure 4). Autoclaved double distilled water used as negative control showed no inhibitory effect or activity. DRE showed significant lower zones of inhibition compared to standard drugs (clarithromycin, amoxicillin) $(\mathrm{p}<0.05)$. It was observed that 


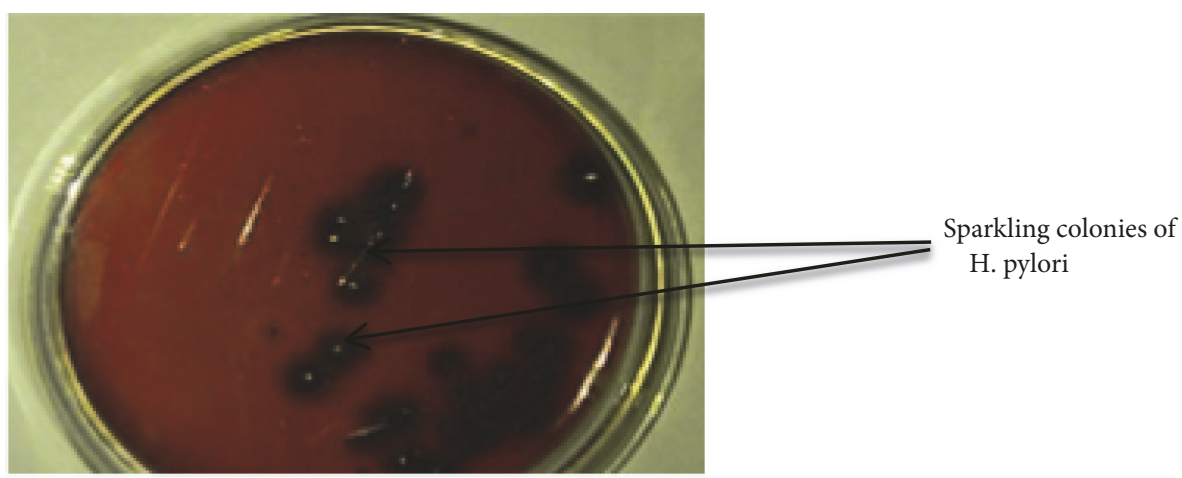

FIGURE 1: H. pylori sparkling colonies on BHI agar incorporated with TTC dye.

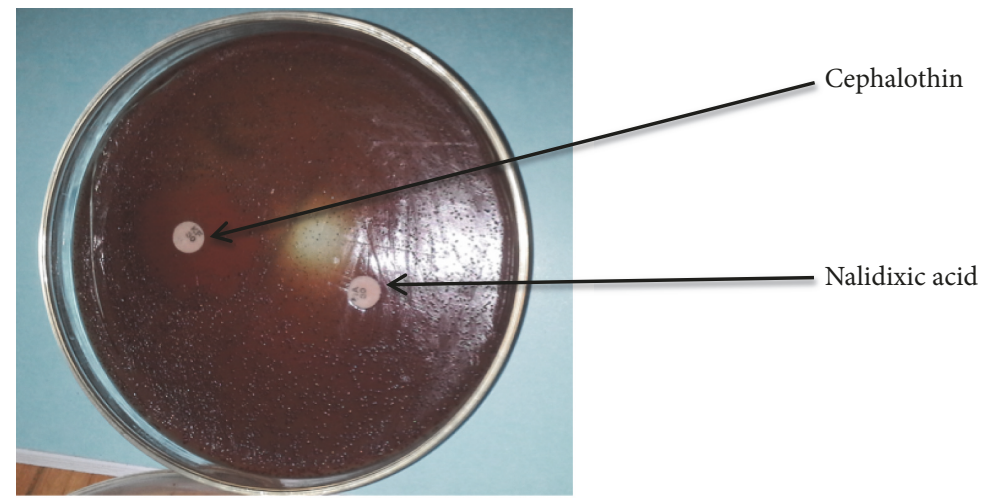

FIGURE 2: Susceptibility test for $H$. pylori using nalidixic acid and cephalothin antibiotic disc.

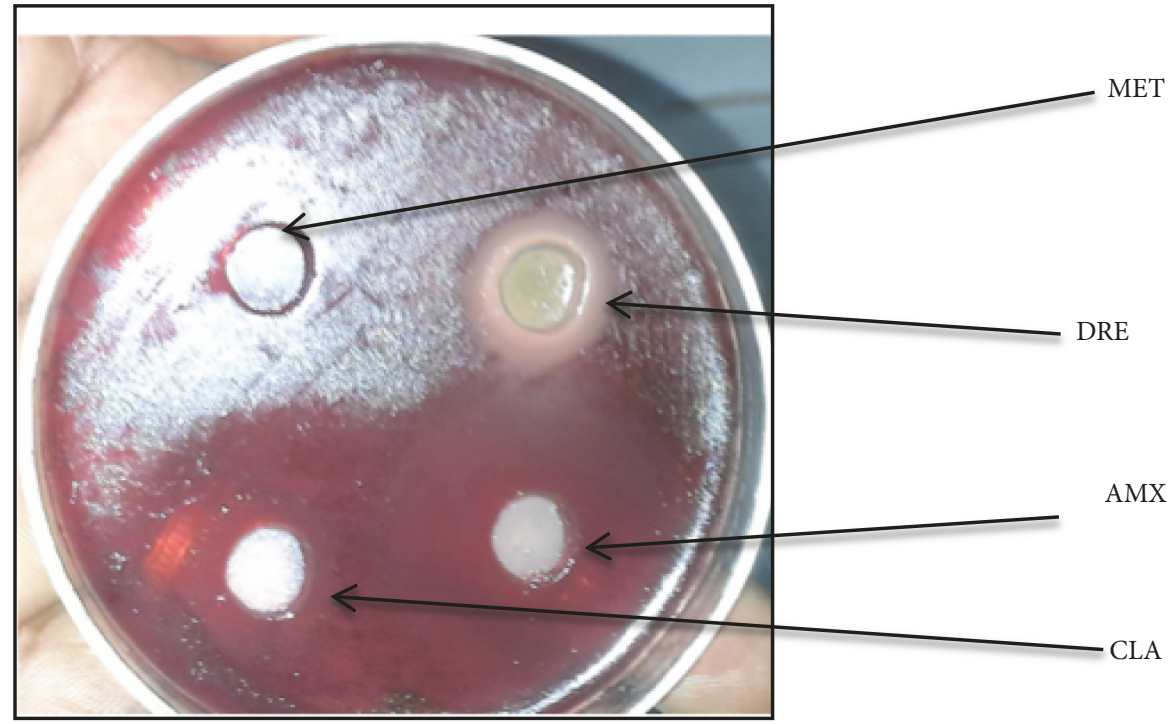

FIGURE 3: Inhibitory effects of Dissotis rotundifolia extract and standard antibiotics on growth of $H$. pylori on BHI agar. Dissotis rotundifolia extract (DRE), amoxicillin (AMX), clarithromycin (CLA), and metronidazole (MET).

metronidazole revealed no zone of inhibition. DRE has an inhibitory effect on growth of $H$. pylori. The inhibitory effect of DRE was observed from a concentration of $200 \mathrm{mg} / \mathrm{mL}$ to $800 \mathrm{mg} / \mathrm{mL}$; meanwhile maximal effect was observed at 400 $\mathrm{mg} / \mathrm{mL}$ (Figure 4).

\section{Discussion}

H. pylori is a major aetiological agent of peptic ulcer that is reported to have developed resistance against some antibiotics in many continents including Africa $[5,16,17]$. The 


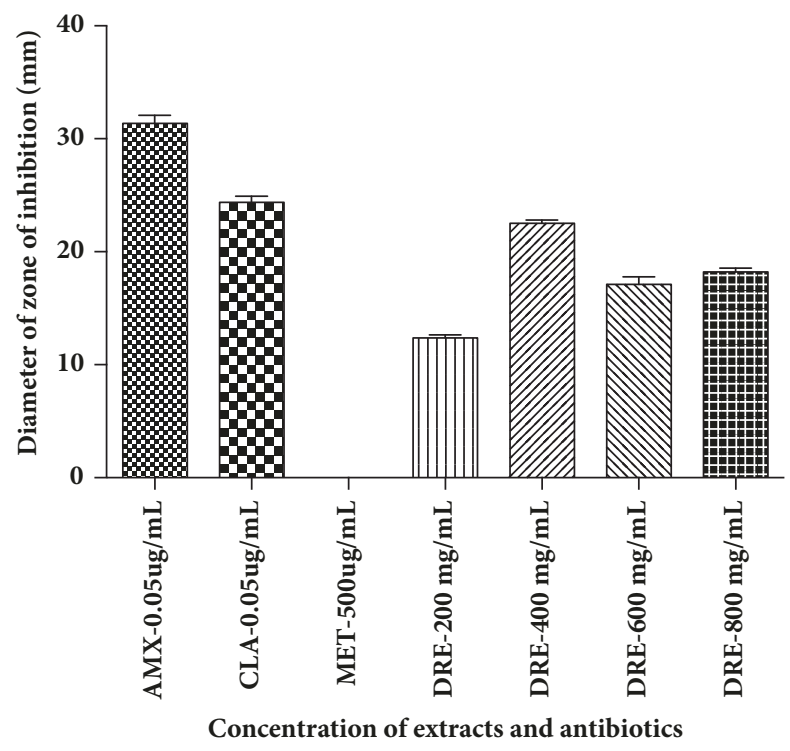

FIGURE 4: Anti-H. pylori activity of Dissotis rotundifolia extract and antibiotics. DRE, Dissotis rotundifolia extract; CLA, clarithromycin; AMX, amoxicillin; MET, metronidazole.

several failed attempts in Ghana to culture the organism have made it difficult to use antimicrobial susceptibility assay and thus generate data on $\mathrm{H}$. pylori resistance profile. To the best of our knowledge, this is the first report on a successful culturing and isolation of $H$. pylori from gastric biopsy in Ghana. It is also the foremost data on the activity of Dissotis rotundifolia extract against clinical isolates of $H$. pylori.

H. pylori bacterium can be distinguished from other species due to its multiple sheathed flagella, strong hydrolysis of urea, and unique fatty acid profile. This organism is one of the few that shows sparkling colonies when cultured on blood amended-Brain Heart Infusion agar incorporated with TTC dye. This characteristic was adopted in the isolation and culturing of the organism. The observation that $H$. pylori grew only at $37^{\circ} \mathrm{C}$ and not $25^{\circ} \mathrm{C}$ or $42^{\circ} \mathrm{C}$ affirms that the organism is neither Helicobacter cinaedi nor Helicobacter fenneliae as reported by Balows et al. [18].

Over the years, many phytomedicines have been used to treat infections due to $H$. pylori particularly in the developing world where this disease is endemic and modern health facilities and services are inadequate. The use of natural products is an attractive alternative treatment regime for $H$. pylori infected individuals. Garlic, honey, and many plant natural products have been found to be valuable in the treatment of $H$. pylori infections [19-24]. One such plant currently used is Dissotis rotundifolia. The whole plant of Dissotis rotundifolia, also known as pink lady, is popularly used for treatment of gastric disorders and other diseases. The plant according to Ansah et al. [25] is nontoxic to delicate organs such as the liver, kidney, and spleen of rats at a dose of 1000 $\mathrm{mg} / \mathrm{kgbwt}$. This plant has been reported to inhibit growth of Staphylococcus aureus, Salmonella typhi, Escherichia coli, Pseudomonas aeruginosa, and other organisms [26]. The ethnomedicinal report on the use of this plant in managing peptic ulcer and the evidence-based data on the antimicrobial activity of the extract on other gastrointestinal tract causing organisms prompted primary investigation into the potential effect of the extract on the growth of Helicobacter pylori.

As part of this research, a flavonoid-rich fraction of Dissotis rotundifolia was screened for its anti- $H$. pylori potential in an in vitro study. Although the results in this study depict statistically lower zones of inhibition for DRE compared to standard drugs [amoxicillin and clarithromycin] $(p<0.05)$, it corroborates the reported ethnomedicinal use of the plant in managing gastric disturbances. The smaller zone of inhibition demonstrated by the flavonoid rich fraction of this plant in vitro, compared to standard antibiotic drugs, does not necessarily imply that the extract demonstrates weak antimicrobial effects in vivo. As with some orthodox drugs, the active ingredients in Dissotis rotundifolia may be pro-drugs; thus its potency could improve in vivo due to biotransformation [27].

C-glycosylflavones compounds, namely, vitexin and isovitexin, have been isolated from the methanolic extract of the whole plant of Dissotis rotundifolia [13]. Vitexin and isovitexin have also been isolated from the leaves of Piper carpunya and are reported to possess pharmacological activity against growth of $H$. pylori [28]. Implicitly the presence of these compounds in Dissotis rotundifolia whole plant extract may be contributing to the inhibitory effects of the plant in this study. The observation that $H$. pylori clinical isolates in this study showed resistance to metronidazole is not contrary to what has been reported in South Africa, Egypt, and many other African countries [5, 16, 17, 29]. This seems to corroborate an unreported emerging phenomenon of $H$. pylori resistance to metronidazole in Ghana and thus calls for an in-depth study of the pattern of drug resistance by $H$. pylori in Ghanaian dyspeptic patients.

In conclusion, this study reports on a first successful isolation of $H$. pylori from Ghanaian dyspeptic patients. It also depicts the fact that Dissotis rotundifolia extract possesses inhibitory potential against growth of clinical isolates of Helicobacter pylori. This finding suggests that Dissotis rotundifolia extract has some therapeutic potential against $H$. pylori infection, which could be explored in managing gastrointestinal problems.

\section{Data Availability}

The data used to support the findings of this study are available from the corresponding author upon request.

\section{Conflicts of Interest}

We declare that we have no conflicts of interest.

\section{Acknowledgments}

Data used in this article is part of a Ph.D. Thesis that was supported by a research grant with reference No. (TDS/35d/v.5/07) from the University of Cape Coast, Ghana. 


\section{References}

[1] J. Robin Warren and B. Marshall, "Unidentified curved bacilli on gastric epithelium in active chronic gastritis," The Lancet, vol. 321, no. 8336, pp. 1273-1275, 1983.

[2] F. Mégraud, "A humble bacterium sweeps this year's Nobel Prize," Cell, vol. 123, no. 6, pp. 975-976, 2005

[3] M. K. Khan and M. Bemana, "Association of Helicobacter pylori infection and gastric carcinoma," Mymensingh Medical Journal, vol. 21, no. 1, pp. 80-84, 2012.

[4] G. Ozbey and C. Aygun, "Prevalence of genotypes in Helicobacter pylori isolates from patients in eastern Turkey and the association of these genotypes with clinical outcome," Brazilian Journal of Microbiology, vol. 43, no. 4, pp. 1332-1339, 2012.

[5] M. Bachir, R. Allem, A. Tifrit et al., "Primary antibiotic resistance and its relationship with cagA and vacA genes in Helicobacter pylori isolates from Algerian patients," Brazilian Journal of Microbiology, vol. 49, no. 3, pp. 544-551, 2018.

[6] T. Rokkas, A. Rokka, and P. Portincasa, "A systematic review and meta-analysis of the role of Helicobacter pylori eradication in preventing gastric cancer," Annals of Gastroenterology, vol. 30, no. 4, pp. 414-423, 2017.

[7] Y. A. Awuku, D. L. Simpong, I. K. Alhassan, D. A. Tuoyire, T. Afaa, and P. Adu, "Prevalence of helicobacter pylori infection among children living in a rural setting in Sub-Saharan Africa," BMC Public Health, vol. 17, no. 1, article 360, 2017.

[8] R. Darko, A. E. Yawson, V. Osei, J. Owusu-Ansah, and S. AluzeEle, "Changing patterns of the prevalence of Helicobacter pylori among patients at a corporate hospital in Ghana," Ghana Medical Journal, vol. 49, no. 3, pp. 147-153, 2015.

[9] H. K. Aduful, S. B. Naaeder, R. Darko, B. N. Baako, J. N. A. Clegg-Lamptey, K. N. Nkrumah et al., "Upper gastrointestinal endoscopy at the korle bu teaching hospital, Accra, Ghana," Ghana Medical Journal, vol. 41, no. 1, article 12, 2007.

[10] B. Fenn, S. S. Morris, and R. E. Black, "Comorbidity in childhood in northern Ghana: Magnitude, associated factors, and impact on mortality," International Journal of Epidemiology, vol. 34, no. 2, pp. 368-375, 2005.

[11] B. N. Baako and R. Darko, "Incidence of Helicobacter pylori infection in Ghanaian patients with dyspeptic symptoms referred for upper gastrointestinal endoscopy.", West African Journal of Medicine, vol. 15, no. 4, pp. 223-227, 1996.

[12] T. N. A. Archampong, R. H. Asmah, E. K. Wiredu, R. K. Gyasi, K. N. Nkrumah, and K. Rajakumar, "Epidemiology of helicobacter pylori infection in dyspeptic Ghanaian patients," Pan African Medical Journal, vol. 20, pp. 1-9, 2015.

[13] G. Rath, A. Touré, M. Nianga, J. L. Wolfender, and K. Hostettmann, "Characterization of C-glycosylflavones from Dissotis rotundifolia by liquid chromatography - UV diode array detection - tandem mass spectrometry," Chromatographia, vol. 41, no. 5-6, pp. 332-342, 1995.

[14] P. R. Murray, E. J. Baron, M. A. Pfaller, F. C. Tenover, R. H. Yolken, and D. R. Morgan, "Manual of Clinical Microbiology (6th edn)," Trends in Microbiology, vol. 3, no. 11, pp. 449-450, 1995.

[15] M. Cheesbrough, District Laboratory Practice in Tropical Countries, Cambridge University Press, Cambridge, UK, 2nd edition, 2006.

[16] C. Njume, A. J. Afolayan, A. M. Clarke, and R. N. Ndip, "Crude ethanolic extracts of garcinia kola seeds heckel (Guttiferae) prolong the lag phase of helicobacter pylori: Inhibitory and bactericidal potential," Journal of Medicinal Food, vol. 14, no. 78, pp. 822-827, 2011.

[17] M. H. Hamrah, M. S. Hamrah, M. H. Hamrah et al., "Prevalence of Helicobacter pylori infection in dyspeptic patients in Andkhoy Afghanistan," Asian Pacific Journal of Cancer Prevention, vol. 18, no. 11, pp. 3123-3127, 2017.

[18] A. Balows, B. I. Duerden, W. W. C. Topley, and S. G. S. Wilson, Topley and Wilson's Microbiology and Microbial Infections: Systematic Bacteriology, Arnold, 1998.

[19] S. Van Vuuren and D. Holl, "Antimicrobial natural product research: A review from a South African perspective for the years 2009-2016," Journal of Ethnopharmacology, vol. 208, pp. 236-252, 2017.

[20] A. Maroyi, "Lippia javanica (Burm.f.) Spreng.: traditional and commercial uses and phytochemical and pharmacological significance in the african and indian subcontinent," EvidenceBased Complementary and Alternative Medicine, vol. 2017, Article ID 6746071, 34 pages, 2017.

[21] O. Cardoso, M. M. Donato, C. Luxo et al., "Anti-Helicobacter pylori potential of Agrimonia eupatoria L. and Fragaria vesca," Journal of Functional Foods, vol. 44, pp. 299-303, 2018.

[22] L. B. Kouitcheu Mabeku, B. Eyoum Bille, T. F. Tchouangueu, E. Nguepi, and H. Leundji, "Treatment of helicobacter pylori infected mice with bryophyllum pinnatum, a medicinal plant with antioxidant and antimicrobial properties, reduces bacterial load," Pharmaceutical Biology, vol. 55, no. 1, pp. 603-610, 2017.

[23] M. Zardast, K. Namakin, J. Esmaelian Kaho, and S. S. Hashemi, "Assessment of antibacterial effect of garlic in patients infected with Helicobacter pylori using urease breath test," Avicenna Journal of Phytomedicine, vol. 6, no. 5, pp. 495-501, 2016.

[24] M. B. Hussain, "Role of Honey in Topical and Systemic Bacterial Infections," The Journal of Alternative and Complementary Medicine, vol. 24, no. 1, pp. 15-24, 2018.

[25] C. Ansah, M. B. Adinortey, J. Asiedu-Larbi, B. Aboagye, D.-B. Asante, and A. K. Nyarko, "In vivo assessment of the toxic potential of Dissotis rotundifolia whole plant extract in Sprague-Dawley rats," Asian Pacific Journal of Tropical Biomedicine, vol. 6, no. 7, pp. 574-579, 2016.

[26] T. A. Abere, P. E. Okoto, and F. O. Agoreyo, "Antidiarrhoea and toxicological evaluation of the leaf extract of Dissotis rotundifolia triana (Melastomataceae)," BMC Complementary and Alternative Medicine, vol. 10, article 71, 2010.

[27] C. F. Tchinda, I. K. Voukeng, V. P. Beng, and V. Kuete, "Antibacterial activities of the methanol extracts of Albizia adianthifolia, Alchornea laxiflora, Laportea ovalifolia and three other Cameroonian plants against multi-drug resistant Gramnegative bacteria," Saudi Journal of Biological Sciences, vol. 24, no. 4, pp. 950-955, 2017.

[28] A. Quílez, B. Berenguer, G. Gilardoni et al., "Anti-secretory, anti-inflammatory and anti-Helicobacter pylori activities of several fractions isolated from Piper carpunya Ruiz \& Pav," Journal of Ethnopharmacology, vol. 128, no. 3, pp. 583-589, 2010.

[29] H. Jaka, J. A. Rhee, L. Östlundh, L. Smart, R. Peck, A. Mueller et al., "The magnitude of antibiotic resistance to Helicobacter pylori in Africa and identified mutations, which confer resistance to antibiotics: systematic review and meta-analysis," $B M C$ Infectious Diseases, vol. 18, no. 1, article 193, 2018. 


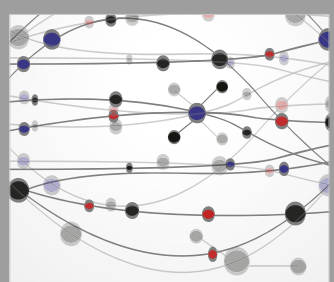

The Scientific World Journal
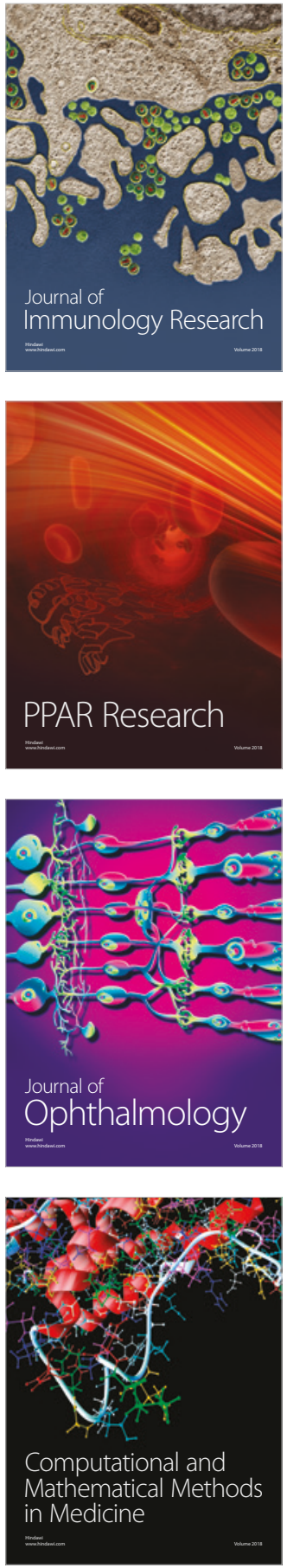

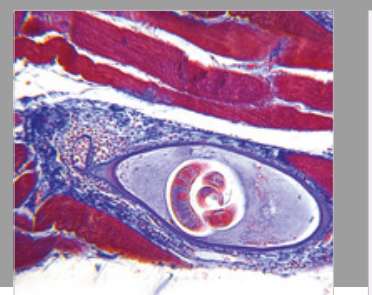

Gastroenterology Research and Practice

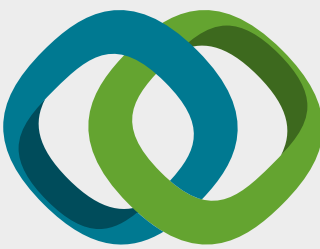

\section{Hindawi}

Submit your manuscripts at

www.hindawi.com
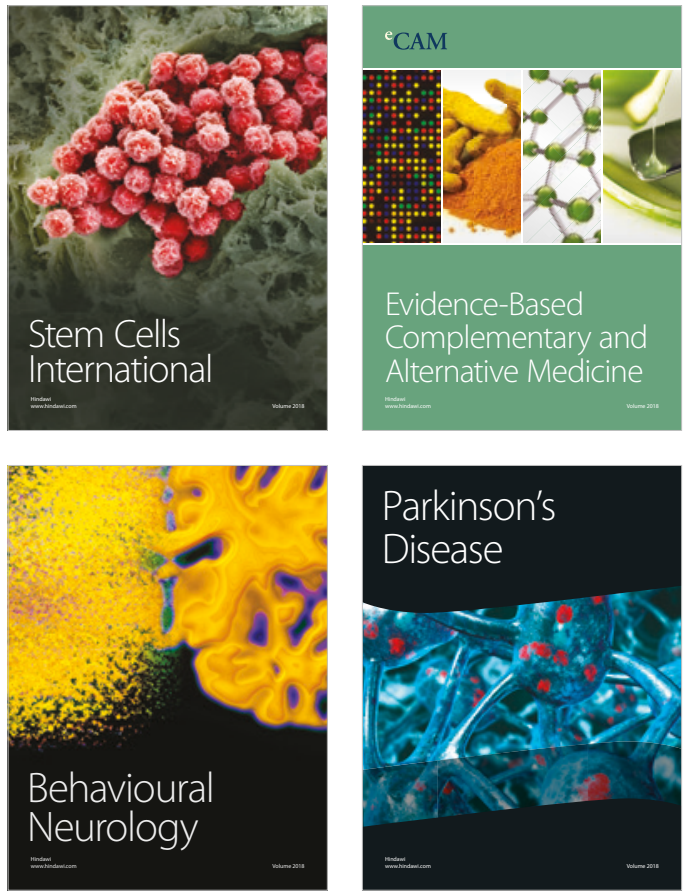

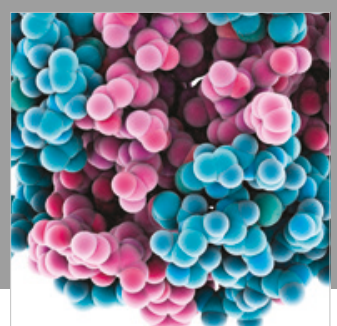

ournal of

Diabetes Research

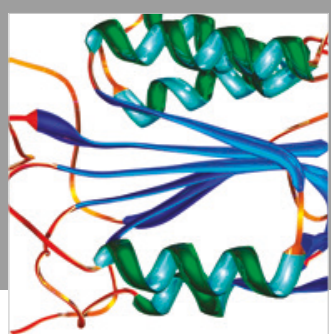

Disease Markers
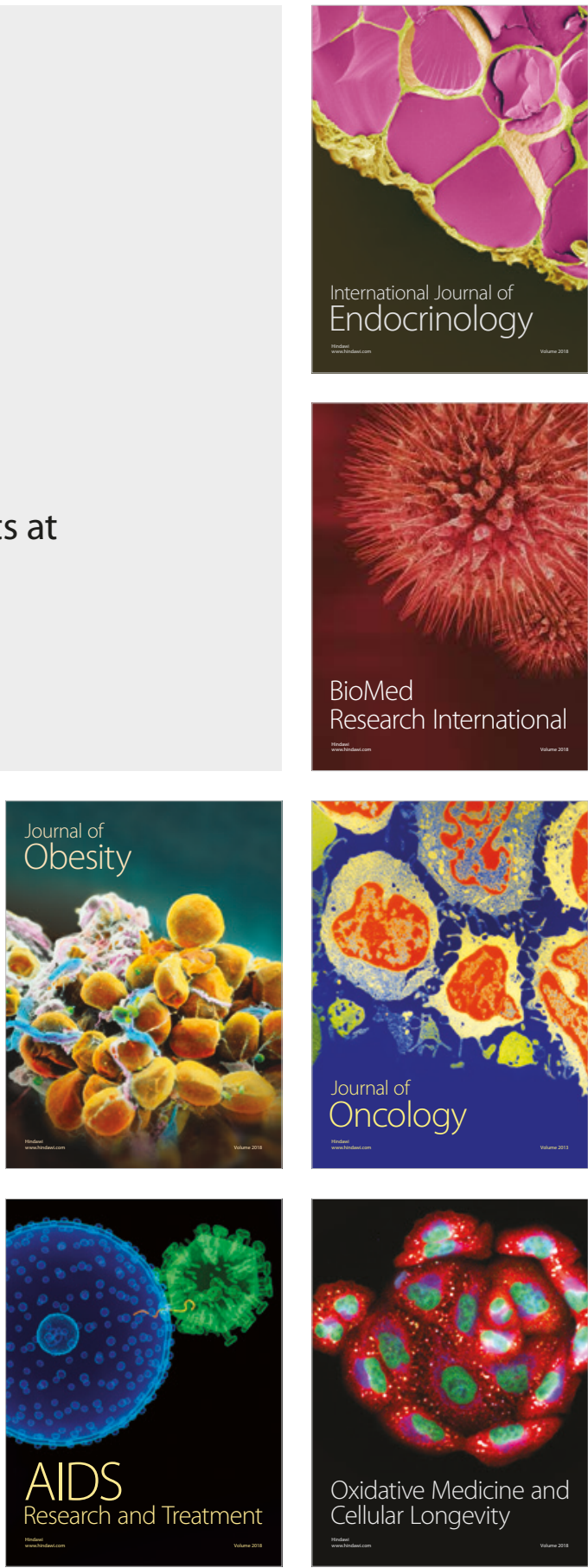